(c) 2021 Universidad Nacional Autónoma de México, Facultad de Estudios Superiores Zaragoza.

Este es un artículo Open Access bajo la licencia CC BY-NC-ND (http://creativecommons.org/licenses/by-nc-nd/4.0/).

TIP Revista Especializada en Ciencias Químico-Biológicas, 24: 1-14, 2021.

https://doi.org/10.22201/fesz.23958723e.2021.328

\title{
Bacterias y hongos endófitos de la familia Cactaceae y sus aplicaciones
}

\author{
Clara Angélica Rodríguez-Mendoza ${ }^{1}$, Luis Ricardo Hernández ${ }^{2}$, \\ Beatriz Pérez-Armendáriz ${ }^{1}$ y Zaida Nelly Juárez ${ }^{3 *}$ \\ ${ }^{1}$ Facultad de Biotecnología. ${ }^{3 *}$ Área de Química, Decanato de Ciencias Biológicas, Universidad \\ Popular Autónoma del Estado de Puebla, 15 Poniente \#1910, Barrio de Santiago. 72410, Puebla, Pue., \\ México. ${ }^{2}$ Departamento de Ciencias Químico Biológicas, Universidad de las Américas Puebla, \\ San Andrés Cholula, 72810, Puebla, México. E-mail: *zaidanelly.juarez@upaep.mx
}

\begin{abstract}
RESUMEN
Las especies de la familia Cactaceae habitan en zonas con altas temperaturas, escasez de agua y suelos con déficit de nutrimentos. Esto es el resultado de procesos complejos como adaptaciones fisiológicas y físicas, además de la coevolución con microorganismos endófitos que habitan en los tejidos vegetales con relevante importancia para las plantas, por facilitar su establecimiento en estratos rocosos, ayudar a la fijación de nitrógeno atmosférico y fósforo a través de bacterias, así como una acción antimicrobiana por parte de los hongos. Los estudios sobre bioprospección de endófitos en las cactáceas aún son escasos, por lo que este trabajo compila la literatura científica sobre bacterias y hongos endófitos en cactus disponible en las bases de datos Dialnet, DOAJ, EBSCO, Google académico, iSEEK, Redalyc, REDIB, Science Direct, SciFinder, SciELO, Springer, Web of Science y Wiley Online Library. La revisión dio como resultado 22 trabajos publicados en un periodo de 33 años, de los que solamente el 36\% analiza su bioactividad. Se destaca el uso de los endófitos en la biotecnología, principalmente para beneficio social (fines agrícolas y médicos), así como de conservación.
\end{abstract}

Palabras clave: microorganismos, cactus, bioactividad potencial.

\section{Endophytes from the Cactaceae family and its application}

\begin{abstract}
Species of the Cactaceae family inhabit areas with high temperatures, water scarcity, and nutrient-deficient soils. This is a result of complex processes such as physiological and physical adaptations, in addition to coevolution with endophytic microorganisms, which are inhabit plant tissues and can have relevant importance for the plant such as their establishment in rocky strata, the atmospheric nitrogen and phosphorus fixation by bacteria, or the antimicrobial action by fungi. Bioprospecting studies on endophytes of cacti are still scarce, so this work compiles the scientific literature on endophytic bacteria and fungi of cacti available in the databases Dialnet, DOAJ, EBSCO, Google académico, iSEEK, Redalyc, REDIB, Science Direct, SciFinder, SciELO, Springer, Web of Science and Wiley Online Library. The review yielded 22 papers published in 33 years; only $36 \%$ of them analyzed their bioactivity. The use of endophytes for biotechnological transfer is highlighted, mainly for social benefit (agricultural and medical purposes), as well as conservation.
\end{abstract}

Keywords: microorganisms, cacti, potential bioactivity.

Artículo recibido el 26 de febrero del 2021.

Artículo aceptado el 17 de junio del 2021. 


\section{INTRODUCCIÓN}

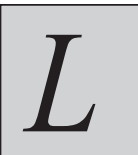

a microbiología es una de las áreas más importantes de las ciencias naturales al permitir conocer a los microorganismos y sus funciones en el balance ecológico terrestre, especialmente de los que forman asociaciones entre ellos y con la mayor parte de los macroorganismos. La genómica, proteómica y metabolómica, junto con los métodos bioquímicos y microbiológicos clásicos, posibilitan un mejor estudio de las complejas redes e interacciones de los microorganismos con su ambiente (Maldonado-Carmona et al., 2019; He et al., 2020). Algunos de estos microorganismos son algas, bacterias y hongos endófitos (Suryanarayanan, 2013).

La etimología de la palabra endófito se deriva del griego endon (dentro) y phyton (planta) y se refiere a microbiomas que se alojan en el tejido interno de una planta (raíz, flor, tallo, frutos o semillas) por transmisión vertical (hacia la descendencia) $\mathrm{u}$ horizontal (no es por la descendencia del huésped), y que establecen una variedad de interacciones biológicas con su fitohospedero según el estado fisiológico de la planta, ya sea por factores ambientales (temperatura, $\mathrm{pH}$, disponibilidad de nutrimentos) o la etapa de desarrollo de ambos; se les encuentra como patógenos latentes, mutualistas, comensales, residentes temporales o saprófitos latentes (Davis \& Shaw, 2008;
Suryanarayanan, 2013; Yadav, 2021). Debido al avance en los estudios moleculares, se han secuenciado una gran cantidad de endófitos que no se han podido cultivar ni aislar (Conn \& Franco, 2004; Pereira, Ibáñez, Rosenblueth, Etcheverry \& Martínez-Romero, 2011), por lo que se ha propuesto una definición más apropiada: los endófitos son un conjunto de genomas microbianos ubicados dentro de los órganos de las plantas (Bulgarelli et al., 2012).

Al establecerse la relación entre los simbiontes (endófito y planta), ambos organismos producen metabolitos secundarios potencialmente tóxicos. Los endófitos pueden producir factores de virulencia, como exoenzimas y metabolitos fitotóxicos, y la planta puede generar defensas mecánicas y/o bioquímicas contra estos factores. Para que los simbiontes puedan coexistir se establece un antagonismo balanceado, el cual depende de la virulencia del endófito y de las variadas defensas de la planta. Estas defensas son influenciadas por factores ambientales y del desarrollo de ambos organismos. Se establece una relación endofítica si los factores de virulencia del microorganismo y las defensas de la planta están en equilibrio; pero si el hospedero presenta senescencia o se encuentra bajo estrés, el microorganismo se expresa como patógeno y en la planta se notan síntomas de enfermedad. Todas estas interacciones se explican en la Figura 1 (Schulz \& Boyle, 2006; Kusari, Hertweck \& Spiteller, 2012; Sánchez-Fernández et al., 2013).

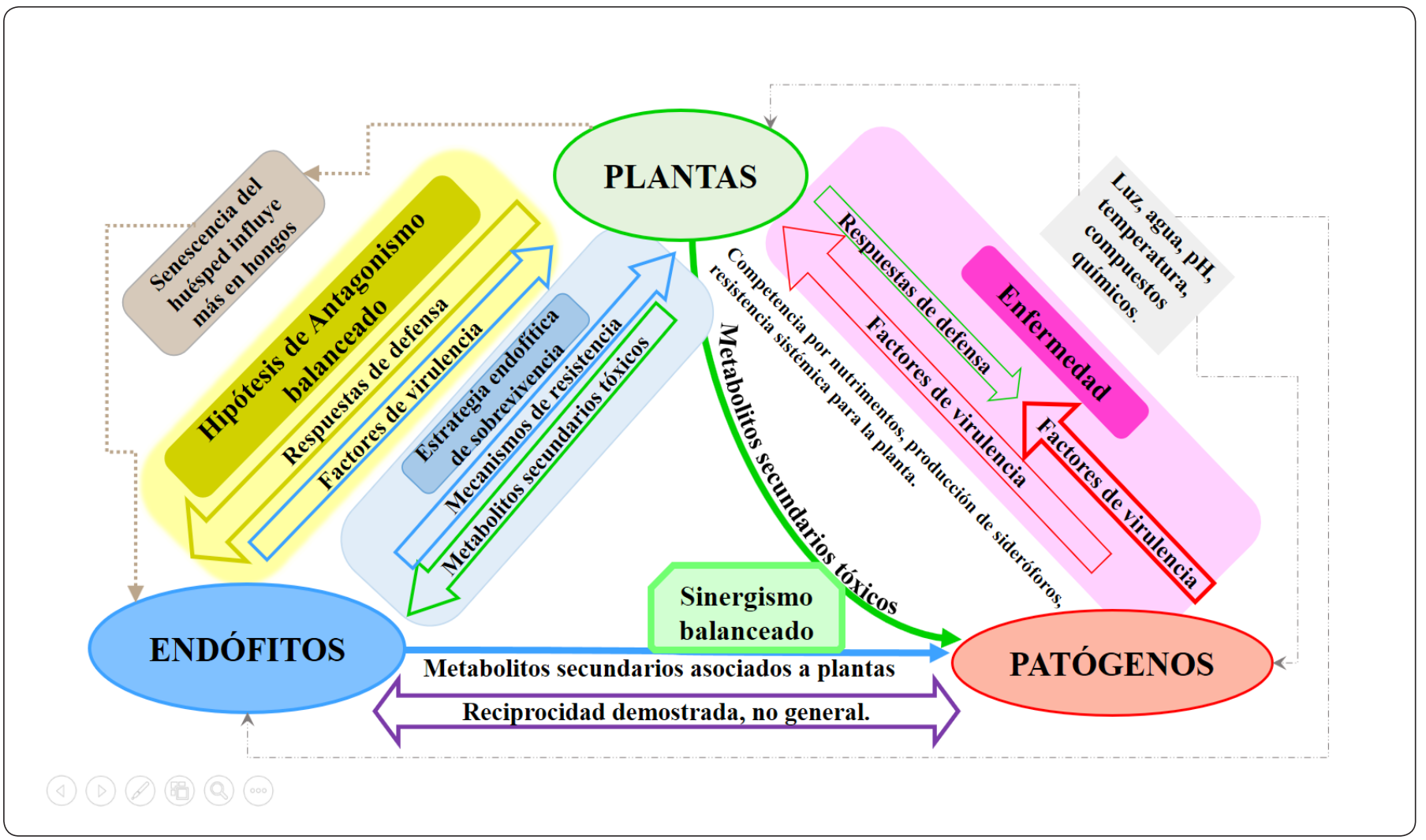

Figura 1. Diagrama de las interacciones entre un microbioma endófito y su planta hospedera. Modificado de Schulz \& Boyle (2006); Puri et al. (2017) y Kusari et al. (2012). 
Las bacterias y hongos endófitos (ByHE) colonizan tejidos sanos de una planta en algún estadio de su ciclo de vida, albergándose en espacios intercelulares, intracelulares y vasculares de los tejidos (Wang et al., 2006; Barrales-Cureño \& De la Rosa, 2014; Pereira, Azevedo \& Souza-Motta, 2017). Las ByHE más estudiados son los que pueden ser aislados de tejidos vegetales cuya superficie fue desinfectada y sus microorganismos fueron aislados. La importancia de la investigación de las ByHE ha sido tal que, se ha propuesto a la "endofitología", como una línea de especialización en las ciencias biológicas (Schouten, 2019).

Se ha demostrado que la presencia de ByHE inducen la estimulación del crecimiento de las plantas mediante la fijación de nitrógeno (solamente bacterias), la producción de fitohormonas, el biocontrol de fitopatógenos en la raíz mediante la producción de agentes antimicrobianos, la producción de sideróforos, la inmunidad contra patógenos, herbívoros y estrés abiótico (Sessitsch, Howieson, Perret, Antoun \& Martínez-Romero, 2002; Rosenblueth \& Martínez-Romero, 2006; Schouten, 2019; Yan et al., 2019; Dini-Andreote, 2020). Particularmente en zonas áridas y semiáridas, algunos estudios demuestran que las ByHE son importantes para las plantas porque les ayudan a soportar el estrés causado por distintas condiciones ambientales adversas como la falta de agua y la alta salinidad, entre otras (Godínez, 2017).
La familia Cactaceae es característica de zonas secas, pues son plantas suculentas nativas de ecorregiones áridas y semiáridas como desiertos, matorrales y selvas secas (Challenger \& Soberón, 2008). Es una de las familias más diversas en el mundo con aproximadamente 1,400 especies; de las que en México se han descrito 797 y el 69\% son endémicas (Comisión Nacional para el Conocimiento y Uso de la Biodiversidad-CONABIO, 2021). La sobrevivencia de los cactus en condiciones extremas de su hábitat se debe a sus adaptaciones morfológicas y fisiológicas: hojas modificadas en espinas y fotosíntesis de plantas con metabolismo ácido de las crasuláceas (CAM, por sus iniciales en inglés: Crassulacean Acid Metabolism), respectivamente (Bezerra, de Azevedo \& Souza-Motta, 2017). Su éxito evolutivo y ecológico también se debe a la interacción que tienen con ByHE al formar un holobionte (a saber, el individuo y su microbiota) que les permite tolerar el bajo contenido de nutrimentos, la presencia de metales pesados y el estrés hídrico y salino; convirtiéndolas en especies dominantes y diversas en hábitats con esas características (Fonseca-García et al., 2016; Godínez, 2017). Por ejemplo, el cactus Cylindropuntia cholla (F.A.C.Weber) F.M.Knuth es colonizado en su zona radical por bacterias como Aarococcus terreus y hongos Agaricomycetes que le ayudan a crecer en estratos rocosos (Puente, Bashan, Lui \& Lebsky, 2004 a). Ésta, junto con otras investigaciones se presentan en la Tabla I.

Tabla I. Especies de cactáceas y sus respectivos endófitos bacterianos y fúngicos, aislados de cada una de ellas.

\begin{tabular}{|c|c|c|c|c|}
\hline \multirow{2}{*}{ Especies de cactus } & \multicolumn{2}{|c|}{ Endófitos (phyla o especies) } & \multirow{2}{*}{$\begin{array}{c}\text { Región de } \\
\text { estudio }\end{array}$} & \multirow{2}{*}{ Referencias } \\
\hline & Bacterias & Hongos & & \\
\hline $\begin{array}{l}\text { Carnegiea gigantea (Engelm.) Britton \& Rose } \\
\text { Consolea sp. } \\
\text { Cylindropuntia acanthocarpa (Engelm. \& } \\
\text { J.M.Bigelow) F.M.Knuth } \\
\text { Cylindropuntia arbuscula (Engelm.) F.M.Knuth } \\
\text { Cylindropuntia bigelovii (Engelm.) F.M.Knuth } \\
\text { Cylindropuntia califórnica (Torr. \& A.Gray) } \\
\text { F.M.Knuth } \\
\text { Cylindropuntia. echinocarpa (Engelm. \& J.M. } \\
\text { Bigelow) F.M. Knuth } \\
\text { Cylindropuntia. fulgida (Engelm.) F.M.Knuth } \\
\text { Cylindropuntia imbricata (Haw.) F.M.Knuth } \\
\text { Cylindropuntia multigeniculata (Clokey) Backeb } \\
\text { Cylindropuntia ramosissima (Engelm.) F.M.Knuth } \\
\text { Cylindropuntia versicolor (Engelm. ex Toumey) } \\
\text { F.M.Knuth } \\
\text { Cylindropuntia whipplei (Engelm. \& J.M.Bigelow) } \\
\text { F.M.Knuth } \\
\text { Echinocereus engelmannii (Parry ex Engelm.) Lem. } \\
\text { E. fasciculatus (Engelm. ex B.D.Jacks.) } \\
\text { L.D.Benson } \\
\text { Mammillaria viridiflora (Britton \& Rose) Boed. } \\
\text { Opuntia engelmannii Salm-Dyck ex Engelm. }\end{array}$ & & 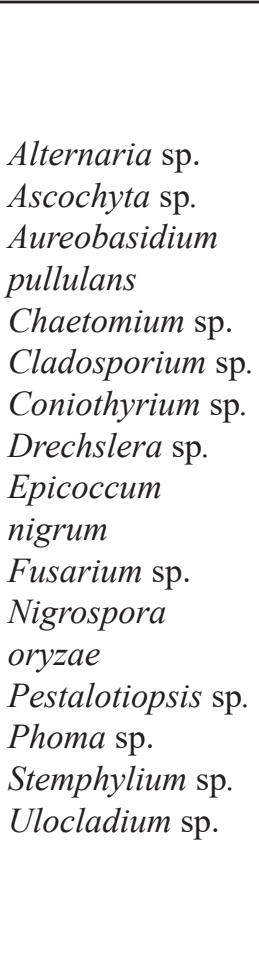 & $\begin{array}{l}\text { Arizona, } \\
\text { EUA. }\end{array}$ & $\begin{array}{l}\text { Suryanarayanan, } \\
\text { Wittlinger \& } \\
\text { Faeth, } 2005\end{array}$ \\
\hline
\end{tabular}


Tabla I. Especies de cactáceas y sus respectivos endófitos bacterianos y fúngicos, aislados de cada una de ellas.

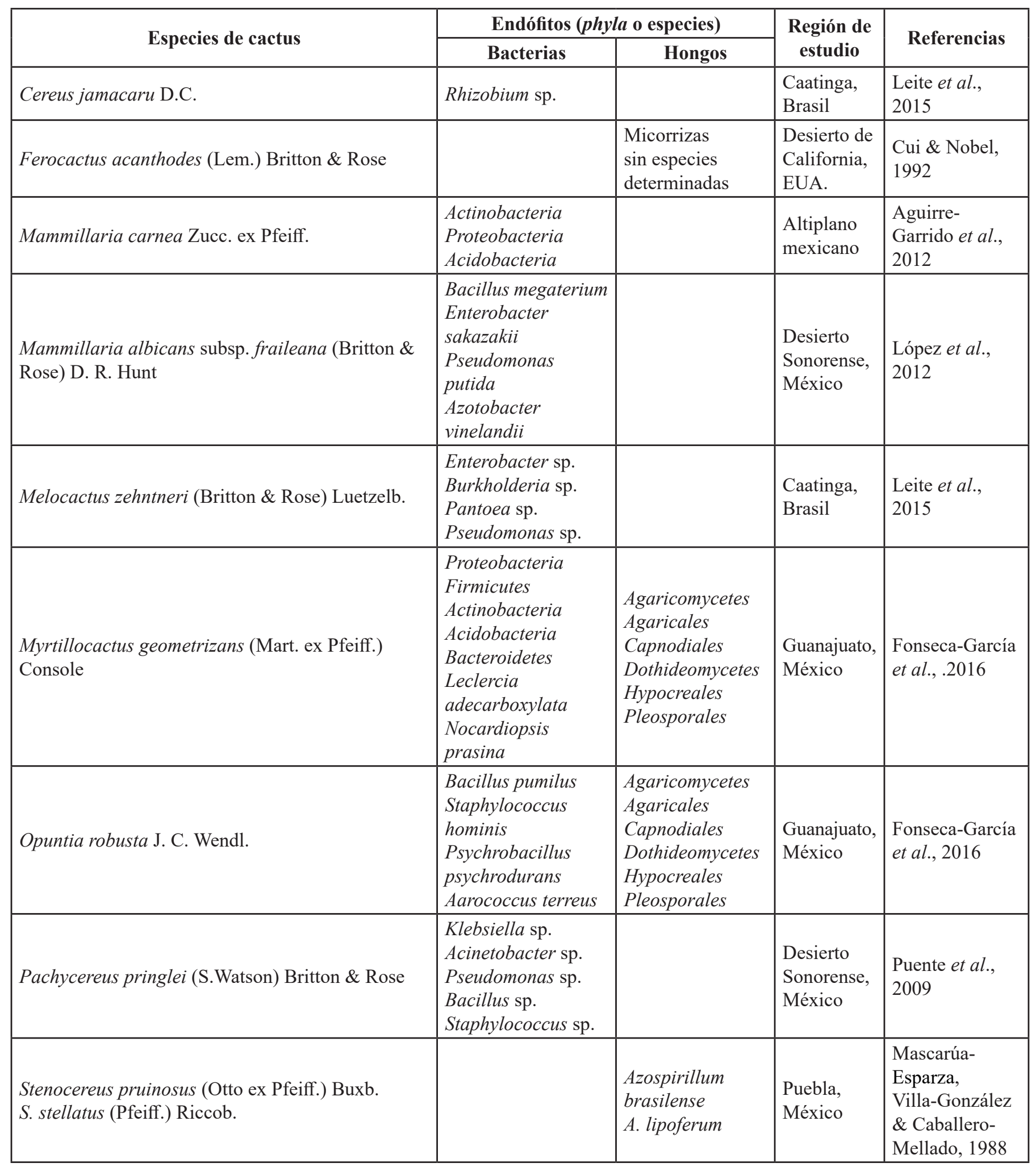

Modificado de Fonseca-García et al. (2016) y Godínez (2017). 
Los cactus cumplen la función de mantenimiento de los ambientes semiáridos y áridos a través de sus servicios ecosistémicos como la protección del suelo contra la erosión e infiltración de agua, alimento y refugio de animales (Pauca, Talavera, Villasante, Quispe \& Laura, 2018) y el nodricismo, cuando la planta nodriza protege a otros organismos al aportar microambientes más favorables (Flores \& Jurado, 2003). Estas características de importancia ecológica han enfocado los estudios de estas especies en su conservación, principalmente proponiendo distintas formas de propagación y cultivo in vitro. En los últimos diez años, se ha incrementado el estudio sobre la actividad biológica de algunos de los metabolitos secundarios producidos por estas plantas, así como la identificación y actividad de su microbioma (Bezerra et al., 2013; Chávez-Ambriz, Hernández-Morales, Cabrera-Luna, Luna-Martínez \& Pacheco-Aguilar, 2016; Bulla et al., 2017; Eke et al., 2019; Camarena-Pozos, Flores-Núñez, López \& Partida-Martínez, 2021).

Lo anterior, revela que es necesario sintetizar y analizar las publicaciones disponibles sobre endófitos en las cactáceas, para contribuir al desarrollo de esta reciente línea de investigación en México. Con esta revisión, se busca ordenar la información existente en este tema para conocer la situación actual sobre su conocimiento, destacando el uso de los organismos endófitos en la transferencia biotecnológica en áreas como la agricultura, la conservación y la salud. Para ello, se hizo la recopilación de información científica desde 1988 hasta enero 2021, sobre endófitos aislados de cactáceas, empleando las principales bases de datos en español e inglés.

\section{BACTERIAS ENDÓFITAS}

Las bacterias endófitas son microorganismos que habitan en las plantas y se estima que existe una alta diversidad de estas (Rosenblueth \& Martínez-Romero, 2006). Según la región donde se encuentre la planta hospedera y de sus propias características, puede albergar más de una especie y en diferentes cantidades ocasionando en ellas, principalmente, efectos como: a) aumento en su capacidad de absorción de nutrimentos del suelo por el incremento y desarrollo de raíces, que ayudan a la solubilización de fosfatos y a la fijación biológica de nitrógeno (Li, Wang, Chen \& Chen, 2008; Schouten, 2019) y b) establecimiento de una relación mutualista que le confiere protección contra factores bióticos y abióticos adversos (Schouten, 2019).

Particularmente hay bacterias endófitas solubilizadoras de fosfato (BSF) orgánico e inorgánico (Goldstein, Lester \& Brown, 2003), las cuales generalmente secretan ácidos orgánicos (Wan \& Wong, 2004) como el butanoico, etanoico, metanoico y propanoico que solubilizan fosfatos minerales (ParedesMendoza \& Espinosa-Victoria, 2010). El mecanismo básico de las BSF para transformar el fósforo insoluble a una forma soluble, es romper los enlaces de $\mathrm{P}$ con iones metálicos de $\mathrm{Al}, \mathrm{Fe}$ y Ca (Restrepo-Correa, Pineda-Meneses \& Ríos-Osorio, 2017).
Otras bacterias especializadas son las fijadoras de nitrógeno, que junto con las cianobacterias y las actinobacterias, forman un grupo único de microorganismos capaces de fijar este elemento químico además de producir metabolitos secundarios (Swarnalakshmi, Senthilkumar \& Ramakrishnan, 2016). Estos microorganismos primero reducen el nitrógeno hasta una forma utilizable mediante la fijación biológica de nitrógeno (FBN), y después lo combinan o fijan en la forma de iones amonio. El proceso de FBN mediado por el complejo nitrogenasa, hace asimilable el nitrógeno atmosférico para otros organismos (Bellenger, Darnajoux, Zhang \& Kraepiel, 2020). Específicamente, las bacterias fijadoras de nitrógeno pueden ser: 1) simbióticas endófitas, que producen nódulos en diferentes especies de leguminosas como las del género Rhizobium, y Frankia, asociadas con Betulaceae, Casuarinaceae y Rhamnaceae, entre otras familias de plantas y 2) de vida libre, como los géneros Azotobacter, Azospirillum, Bacillus y Clostridium (Puri, Padda \& Chanway, 2017; Soumare et al., 2020).

También existen bacterias que promueven el crecimiento vegetal (PGPB por sus iniciales en inglés: Plant Growth Promoting Bacteria) mediante distintos mecanismos fisiológicos como: a) fijación de nitrógeno, b) solubilización de fósforo y c) producción de quitinasas, fitohormonas, glucanasas, sideróforos, compuestos orgánicos volátiles y antibióticos (Pitiwittayakul \& Tanasupawat, 2020). Particularmente en zonas áridas y semiáridas, Kobayashi, Reedy, Bick \& Oudemans (2002) demostraron que las PGPB son muy importantes para el establecimiento de muchas especies de plantas.

\section{Bacterias endófitas de las cactáceas}

A pesar de que las PGPB son esenciales para el establecimiento de plantas en zonas áridas y semiáridas, falta más investigación sobre su presencia en las cactáceas. Lima, Weber, Correia, Soares \& Senabio (2015) identificaron en la cactácea columnar Cereus jamacaru DC., cepas bacterianas como Rhizobium, Burkholderia, Enterobacter, Pseudomonas y Pantoea, que no aumentaron significativamente la biomasa del cactus durante seis meses de cultivo, sin embargo, estas bacterias mostraron una posible actividad solubilizadora de fosfatos.

Por otro lado, Fonseca-García, Desgarennes, Flores-Núñez \& Partida-Martínez (2018) analizaron el microbioma de plantas CAM, con una separación entre los microorganismos presentes en las siguientes zonas: a) rizosfera, b) endosfera radicular, c) endosfera del tallo y d) filosfera (partes aéreas de las plantas). Las cactáceas que estudiaron fueron Myrtillocactus geometrizans (Mart. ex Pfeiff.) Console y Opuntia robusta J. C. Wendl. Los linajes de las bacterias y las arqueas encontrados en ambas especies fueron Actinomycetales, Bacillales, Burkholderiales, Enterobacteriales, Pseudomonadales, Rhizobiales, Sphingobacteriales y Xanthomonadales, entre otros. De acuerdo con la diversidad de estos linajes, se determinó 
que uno de los factores que influyen en la composición bacteriana de estas plantas es la zona de las plantas de donde provienen, ya que la diversidad microbiana fue mayor en la rizosfera, y menor en la endosfera.

\section{HoNGOS ENDÓFITOS}

Los hongos endófitos son microorganismos que colonizan los tejidos vivos internos de las plantas y pueden contribuir a la protección de su hospedera contra factores: a) bióticos como patógenos y herbívoros, b) abióticos como el estrés salino y térmico o la presencia de metales (Ramos-Garza et al., 2016; Yan et al., 2019). También, se consideran hongos endófitos a los que en alguna etapa de su ciclo de vida, subsisten en su hospedera sin producir síntomas de enfermedad (Petrini, 1991; Porras-Alfaro \& Bayman, 2011). Los espacios intercelulares y las conexiones apoplásticas son el nicho primordial de estos hongos, en donde se alimentan de los nutrimentos que circulan por los haces vasculares de las plantas que habitan (Saikkonen, Faeth, Helander \& Sullivan, 1998).

Algunos estudios como el de Schulz, Römmert, Dammann, Aust \& Strack (1999) demuestran que, a veces, la condición saprófita del hongo endófito que se hospeda en ciertos árboles cambia a efectos negativos cuando la planta se vuelve susceptible al presentar desórdenes nutricionales o estrés hídrico y el hongo la puede invadir. De tal forma, que existen hongos "endófitos temporales" o "patógenos latentes" (Márquez, Bills, Herrero \& Zabalgogeazcoa, 2012), al considerar que la latencia se refiere a infecciones "letargadas" y asintomáticas por algún tiempo. Estos hongos pasarían de su estado quiescente a patogénico cuando las condiciones resulten propicias para el huésped y/o desfavorables para la planta. Hay ocasiones en las que bajo determinadas condiciones ambientales, un hongo endófito puede comportarse como patógeno en otra condición ambiental dentro de la misma hospedera u en otra distinta (Begoude, Slippers, Wingfield \& Roux, 2011; Delaye, García-Guzmán \& Heil, 2013).

La protección del hongo a su hospedera se puede realizar por medio de tres mecanismos: 1) directo, a través de enzimas y/o metabolitos secundarios con acción anti-patógena, originados en el hongo; 2) indirecto, inducen o aumentan la expresión de los mecanismos de defensa fisiológicos o químicos inherentes a su hospedera; y 3) ecológico, mediante la depredación, el hiperparasitismo y la ocupación del nicho ecológico (SánchezFernández et al., 2013).

\section{Hongos endófitos de las cactáceas}

Uno de los géneros más estudiados de la familia Cactaceae, por su diversidad e importancia económica, es Opuntia. Por ejemplo, Ratnaweera, de Silva, Williams \& Andersen (2015) analizaron la actividad antimicrobiana de los hongos endófitos del cactus invasivo Opuntia dillenii (Ker Gawl.) Haw. e identificaron dos especies: Aspergillus niger y Fusarium sp., la primera con mayor colonización en los cladodios del cactus y la segunda en los pistilos de sus flores. El endófito Fusarium sp. mostró mejor acción antimicrobiana que A. niger contra Bacillus subtilis y Staphylococcus aureus, lo cual se atribuye al compuesto identificado mediante cromatografía como equisetina (Ratnaweera et al., 2015).

Para otras especies de cactáceas, Bezerra et al. (2013) identificaron 59 taxa de hongos endófitos del cactus columnar Cereus jamacaru del bosque tropical seco brasileño. Las especies de hongos dominantes fueron Cladosporium cladosporioides y Fusarium oxysporum; seguidas de Acremonium implicatum, Aureobasidium pullulans, Trichoderma viride, Chrysonilia sitophila y Aspergillus flavus. Por primera vez se registraron 47 especies como hongos endófitos de una cactácea, lo cual sugiere que $C$. jamacaru alberga una comunidad fúngica altamente diversa. Las curvas de acumulación de especies demuestran que, según los autores, el estudio subestima la diversidad de endófitos; por lo que sugieren realizar muestreos más exhaustivos.

El mencionado trabajo de Fonseca-García et al. (2018), reporta varios linajes de hongos endófitos del cactus columnar Myrtillocactus geometrizans y el nopal Opuntia robusta, como Botryosphaeriales, Capriodiales, Chaetosphaeriales, Dothideomycetes, Hypocreales y Pleosporales, entre otros. Los distintos ensambles de estos hongos parecen estar influenciados por la biogeografía de sus hospederas, pues la diversidad fúngica varió según la ubicación de los cactus; resultando dos grupos principales: los estadounidenses y los mexicanos. Otro factor importante que podría explicar la diferencia de los ensambles de la endosfera del tallo, fue la época del año, ya que en la temporada lluviosa no se registraron los linajes que se presentaron durante la época seca, o bien fueron menos abundantes.

\section{USOS Y APLICACIONES DE ALGUNOS ENDÓFITOS DE CACTÁCEAS}

La investigación sobre los endófitos de las cactáceas es escasa y más aún su efecto en otros organismos, sus hospederas o su bioactividad en general. A continuación, se describen aplicaciones potenciales basadas en estudios de endófitos hallados en estas y otras especies de plantas, cuya actividad ha sido probada experimentalmente y/o escalada a nivel productivo.

\section{Crecimiento y desarrollo de plantas}

Puente et al. (2004 a) demostraron que algunas bacterias endófitas (Bacillus chitinolyticus, Citropbaacter sp., Pseudomonas putida) de la cactácea conocida como cardón o Pachycereus pringlei (S.Watson) Britton \& Rose, pueden disolver fósforo y transformarlo en formas asimilables para las plantas. Otras bacterias aisladas de la misma especie de cactus, son capaces de degradar roca (Azospirillum brasilense, Bacillus pumilus) y fijar nitrógeno atmosférico (Bacillus subtilis). Estas capacidades fisiológicas pueden estar relacionadas con el establecimiento de plantas en estratos rocosos (Puente, Li \& Bashan, 2004 b). 
Asimismo, López, Tinoco-Ojanguren, Bacilio, Mendoza \& Bashan (2012) trabajaron con el cactus mexicano Mammillaria albicans subsp. fraileana (Britton \& Rose) D. R. Hunt, aportando evidencia experimental de que la inoculación de bacterias endófitas nativas (especies que se encuentran en su área de distribución natural u original -histórica o actualsegún su potencial de dispersión natural, y forman parte de las comunidades bióticas naturales del área) puede estimular el crecimiento del cactus. Esto mediante la movilización de elementos del sustrato rocoso de la planta como $\mathrm{Na}, \mathrm{PyFe}$, lo cual puede incrementar su actividad fotosintética y la acumulación de biomasa. Los endófitos identificados por la secuenciación total del gen 16S rRNA, fueron 14 morfotipos; dentro de los que destacan Azotobacter vinelandii M2Per, Pseudomonas putida M5TSA y Bacillus megaterium M2PCa como degradadoras de rocas riodacitas. Además, los cactus inoculados con la variante de $P$. putida, mostraron más acumulación de nitrógeno total que los inoculados con la bacteria fijadora de nitrógeno control.

Por otro lado, Camarena-Pozos, Flores-Núñez, López, LópezBucio \& Partida-Martínez (2019) aislaron de los cactus Opuntia robusta y Myrtillocactus geometrizans, bacterias endófitas de los phylaActinobacteria, Firmicutes y Proteobacteria. Comprobaron que estas endófitas emiten compuestos orgánicos volátiles (ésteres, alcoholes, compuestos azufrados y nitrogenados) que influyen en el crecimiento y el desarrollo (longitud y número de raíces, biomasa, etc.) de algunas herbáceas como Arabidopsis thaliana (L.) Heynh. y Nicotiana benthamiana Domin. Por lo tanto, algunos de estos compuestos son moléculas prometedoras para la producción sostenible de cultivos en regiones áridas y semiáridas (Camarena-Pozos et al., 2019).

Flores-Núñez et al. (2020) realizaron un estudio metagenómico de los endófitos de cactus del centro de México, donde señalan algunos de los mecanismos por los que algunas bacterias (encima y por debajo del suelo) sobreviven y colonizan plantas de ecosistemas áridos y semiáridos. Sus resultados indican que hay una diferencia funcional en los grupos microbianos del suelo, la rizosfera y la filosfera del cactus; agrupando así los linajes en grupos funcionales específicos: productores de biofilm, bacterias fototróficas y diazotróficas. Estos grupos influyeron en la diversidad microbiana y los autores sugieren que pueden intervenir en el crecimiento, la salud y la productividad de las cactáceas producidas en invernadero.

Aunque Kavamura et al. (2013) aislaron 48 cepas bacterianas como Bacillus, Brevibacillus, Cellulosimicrobium, Enterobacter, Paenibacillus, Pantoea y Virgibacillus de la rizosfera de los cactus Cereus jamacaru, Melocactus sp. y Pilosocereus gounellei (F.A.C.Weber ex K.Schum.) Byles \& G. D. Rowley, algunos de estos géneros (Bacillus, Enterobacter, Pantoea) también se han identificado como endófitos de cactáceas (Puente et al., 2004 a; López et al., 2012; Lima et al., 2015; Fonseca-García et al., 2018). El 65\% de esas cepas bacterianas crecieron en un medio con reducida disponibilidad de agua y un $65 \%$ produjeron exopolisacáridos. En el mismo estudio se inocularon algunas de estas bacterias en plantas de Zea mays L. y solamente tres cepas de Bacillus sp. (LMA3, LMA42 y LMA52) y una de Pantoea sp. (LMA28), el resultado fue un aumento significativo del área foliar del maíz en comparación con las plantas no inoculadas con las bacterias. De estas, en las plantas de maíz, solo la cepa LMA3 incrementó los tres parámetros analizados (área foliar, longitud del tallo y biomasa seca de brotes). Además, la inoculación de esta cepa parecía haber protegido a la planta contra los efectos negativos de la desecación (Kavamura et al., 2013).

Kavamura et al. (2013) también cuantificaron: a) la producción de ácido indolacético en las cepas bacterianas que aislaron de la rizosfera de los cactus brasileños, con valores superiores a $51 \mu \mathrm{g} \mathrm{mL}^{-1}$ para el $4 \%$ de ellas, y b) la solubilización de Ca-P que fue alta para el $6 \%$ de estas endófitas. Al inocular estas cepas en plantas de Z. mays, la producción del ácido indolacético de las bacterias se correlacionó positivamente con la longitud del tallo y con la solubilización del fósforo en las plantas de maíz. El ácido indolacético es una fitohormona reguladora de la división celular, formación de raíces y el crecimiento. Actualmente este ácido es de las auxinas más usadas con fines agrícolas y se sintetiza químicamente, causando contaminación del entorno donde se produce y se usa, por lo que se buscan métodos responsables ambientalmente para su obtención (Ayala et al., 2020).

Recientemente, Camarena-Pozos et al. (2021) identificaron compuestos volátiles (terpenos, alcoholes, ésteres, cetonas) en hongos endófitos de $O$. robusta y $M$. geometrizans, que en su mayoría son producidos por las clases Sordariomycetes, Eurotiomycetes y Dothiomycetes. Algunos de los compuestos aislados como el canfeno y el benzoato de bencilo, tuvieron un efecto positivo en el crecimiento de las raíces y en general de la biomasa de la herbácea Arabidopsis thaliana.

\section{Incremento en la germinación de semillas y la floración} Chávez-Ambriz et al. (2016) obtuvieron aislados bacterianos de la rizosfera de Mammillaria magnimamma Haw. y Coryphantha cornifera (DC.) Lem., pertenecientes al género Bacillus. Todas las bacterias aumentaron la germinación de las semillas hasta un $34.3 \%$ más, con respecto a las semillas no inoculadas con los bacilos. También se mostró un efecto positivo sobre la floración del cactus al inocular una de estas bacterias en plantas de Mammillaria zeilmanniana Boed.; ya que, en un par de meses dentro del período de un año, aumentó hasta un $31 \%$ el número de plantas en floración con respecto a las plantas sin bacterias inoculadas. Esto sugiere que la inoculación de estas rizobacterias podría usarse en programas de conservación de especies de cactáceas en alguna categoría de riesgo o para el mantenimiento de sus poblaciones (ChávezAmbriz et al., 2016). 


\section{Control de plagas}

Silva-Hughes et al. (2015) encontraron en el cactus Opuntia humifusa (Raf.) Raf., una especie de hongo endófito (Biscogniauxia mediterranea) que demostró tener una moderada actividad antifúngica, al menos en fase experimental, contra el patógeno Phomopsis obscurans que causa el tizón en las hojas de la fresa. Probablemente en otras cactáceas existan más hongos endófitos con estos efectos; puesto que se ha demostrado la existencia de los mismos en plantas como pastos, que pueden actuar como agentes de biocontrol de ciertos insectos (Clay, 1989). En cuanto a las bacterias, Shahid et al. (2017) aislaron cepas de Pseudomonas aurantiaca de un cactus paquistaní, en las que identificaron metabolitos secundarios como la fenazina-1-ácido carboxílico, que mostró una función antifúngica en plantas de trigo.

\section{Tolerancia a la sequía}

Recientemente, Eke et al.(2019) aislaron 18 especies de bacterias del cardón silvestre Euphorbia trigona Mill, pertenecientes a 13 géneros como Bacillus, Lysinibacillus, Enterobacter, Stenotrophomonas, Lelliottia y Pseudomonas. Al inocular estas endófitas en plantas de tomate, se produjeron cambios benéficos en las plantas en su estado oxidativo, la función estomática y del fotosistema II, la temperatura interna de la hoja y el contenido relativo de agua. Esto sugiere un efecto fisiológico positivo en el tomate por parte de las endófitas, contra el estrés por humedad. Así, en este estudio los autores proponen usar la cepa de Bacillus amyloliquefaciens como bioinoculante de bajo costo para contrarrestar los problemas de sequía y elevar la producción de ciertos cultivos, como por ejemplo el tomate donde fue probada la bacteria. En el mismo trabajo, se identificó por primera vez a Bacillus xiamenensis como endófito de una planta. A pesar de que las bacterias fueron aisladas de E. trigona, que no es una cactácea pero sí una suculenta característica de hábitats secos, podría compartir algunos endófitos con ciertos cactus. Esto tal y como lo demuestra un estudio con el hongo patógeno Fusarium oxysporum hallado por primera vez en Euphorbia mammillaris L. y que es típico de cactus como Astrophytum myriostigma Lem., Epiphyllum hookeri Haw. y Cereus repandus (L.) Mill. (Bertetti, Ortu, Gullino \& Garibaldi, 2017).

Recuperación de poblaciones y restauración de ecosistemas Varias especies de cactáceas se encuentran bajo alguna categoría de riesgo, debido principalmente a su comercio ilegal y la pérdida de su hábitat, por lo que los estudios de propagación in vitro son muy comunes para poder reintroducir las especies en su hábitat original. Por lo tanto, si se vincula este tipo de investigaciones con las de microorganismos endófitos, la probabilidad de recuperar y reestablecer poblaciones de cactáceas vulnerables a los distintos problemas ambientales, podría ser mayor. Incluso para establecer Unidades de Manejo para la conservación y aprovechamiento de la vida silvestre (UMA), debido a que estas plantas son altamente cotizadas por su importancia hortícola (Ruvalcaba-Ruiz, Rojas-Bravo \& Valencia-Botín, 2010; Godínez, 2017; Rodríguez-Ruíz et al., 2018).

Los estudios de PGPB en cactáceas indican que la relación entre endófitos y plantas del desierto podría ser más común (Pereg, de-Bashan \& Bashan, 2016; Enebe \& Babalola, 2018). De modo que las bacterias endófitas de cactus pioneros como Mammillaria albicans subsp. fraileana, Opuntia cholla, Pachycereus pringlei y Stenocereus thurberi (Engelm.) Buxb., aportarían una ventaja ecológica sobre superficies de roca estéril porque les permitiría crecer donde otras plantas no pueden hacerlo (Bashan, Li, Lebsky, Moreno \& De Bashan, 2002; López et al., 2012). Se ha demostrado que las semillas de muchas especies de plantas contienen diversidad de endófitos que les ayudan a germinar, lo que probablemente ocurra también en las cactáceas (Li, Parmar, Sharma \& White, 2019). Esto es una línea de investigación actual para identificar y después usar los microorganismos para la restauración activa de los ecosistemas, a través de la colonización y establecimiento de plantas pioneras en suelos degradados o donde ya exista roca desnuda (Puente, Li \& Bashan, 2009; López et al., 2012).

\section{Biorremediación como uso potencial}

En cuanto a la bioactividad de las cactáceas y sus endófitos, falta mucho por analizar. Las funciones de fitoextracción de metales pesados y fitoestabilización de residuos tóxicos, han sido estudiadas en bacterias endófitas de familias vegetales distintas a la Cactaceae. Por ejemplo, las PGPB pueden servir como componentes valiosos en la biorremediación de suelos y aguas contaminados, así como en la revegetación y reforestación de tierras degradadas. La mayor utilidad potencial de estas bacterias radica en su estrecha asociación e influencia positiva en el crecimiento de las plantas. Por ejemplo, se ha demostrado que las PGPB endófitas y de la rizosfera aumentan la biomasa de ciertas plantas, y contribuye a la degradación de contaminantes orgánicos (De Bashan, Hernández \& Bashan, 2012; Li, Wei, Shen \& Zhou, 2012; Puri et al., 2017).

Por otro lado, existen hongos que degradan colorantes de aguas residuales a través de exoenzimas o por bioabsorción (Cardona, Osorio \& Quintero, 2009). Algunas de esas enzimas son lacasas provenientes de hongos endófitos y no endófitos, demostrándose su potencial para degradar tintes de origen industrial (Bulla et al., 2017; Bettin et al., 2019). Particularmente, Tochhawng, Mishra, Passari \& Singh (2019) compilaron al menos cinco hongos endófitos con reportes de biodegradación de tintes sintéticos, como Marasmius cladophyllus, Myrothecium verrucaria y Phlebia formosus.

Muthezhilan, Vinoth, Gopi \& Jaffar Hussain (2014) purificaron parcialmente lacasas de distintas cepas de hongos endófitos y encontraron que la de Fusarium sp. puede degradar los tintes 
textiles utilizados, más que las otras cepas analizadas. Este género de hongo endófito ya ha sido identificado en algunas cactáceas, como se mencionó en párrafos anteriores (Bezerra et al., 2013; Ratnweera et al., 2015; Bertetti et al., 2017); por lo tanto, se sugiere que sería posible aislar una enzima o compuesto similar a la lacasa en esas u otras especies de cactus. Además, la enzima usada por Muthezhilan et al. (2014) fue aislada de hongos endófitos de plantas provenientes de dunas costeras, un ecosistema donde puede haber cactus como Mammillaria gaumeri (Britton \& Rose) Orcutt que es endémica de matorrales de dunas costeras y bosques caducifolios secos tropicales de Yucatán (Ferrer-Cervantes et al., 2012).

\section{Potencial uso farmacológico}

Hay evidencia de que algunas especies de cactus producen metabolitos secundarios con beneficios médicos como antiinflamatorios y anticancerígenos (Shedbalkar, Adki, Jadhav \& Bapat, 2010; Salazar et al., 2011; De Castro et al., 2012; Kim, Jho, Choi \& Nam, 2013; Zareisedehizadeh, Tan \& Koh, 2014; Ríos-León, Fuertes-Ruiton, Arroyo \& Ruiz, 2017). Asimismo, se han identificado en algunas cactáceas, bacterias endófitas como Pseudomonas, género del que ciertas especies producen metabolitos secundarios de los que se han aislado compuestos como: 1) antibióticos (Singh, Shrivastava, Yadav \& Srivastava, 2020); 2) emomicinas, una familia relativamente nueva de antibióticos de naturaleza lipopeptídica con acción antifúngica (Miller et al., 1998; Samad, Antonielli, Sessitsch, Compant \& Trognitz, 2017); y 3) ácido bórico y 2-amino-3quinolincarbonitrilo, cuyo efecto resultó antibacteriano(Fitriani, Ihsan \& Hamdiyati, 2015). Además, se ha demostrado actividad antibiótica de ciertos compuestos de $P$. fluorescens aislada del algodón (Devi, 2019).

\section{Conclusiones}

Esta revisión evidencia que, hasta ahora, existen reportes de la presencia de endófitos en varias cactáceas. Algunos de esos trabajos sólo reconocen el phyllum, clase, orden o género de las bacterias u hongos endófitos encontrados en los cactus. De los 22 trabajos considerados en esta revisión, la mayoría (12 estudios) analizaron bacterias; mientras que la minoría (8 publicaciones) se refieren a hongos, y solamente 2 de ellos, identifican bacterias y hongos. El 18\% de los trabajos señala la actividad biológica de los endófitos en las mismas especies de cactáceas de las que fueron aislados, y otro $18 \%$ se refiere al efecto de los endófitos en algunas herbáceas o en un hongo patógeno del cultivo de la fresa. Dado que la mayoría de las publicaciones (13 trabajos) solamente registran la presencia de hongos y/o bacterias endófitas, es evidente la importancia de investigar su bioactividad e identificar los compuestos activos. Por otro lado, desde principios de este siglo se producen nuevos fármacos con compuestos activos producidos por microorganismos endófitos (Martínez-Klimova, RodríguezPeña \& Sánchez, 2017). Así, existe la posibilidad de que alguna bacteria $\mathrm{u}$ hongo endófito de los cactus, generen compuestos químicos con propiedades medicinales. Incentivar la investigación en este sentido, contribuirá a lograr uno de los Objetivos de Desarrollo Sustentable de la Organización de las Naciones Unidas que es generar buena salud y bienestar, mediante la búsqueda de nuevos medicamentos de origen microbiano para combatir la resistencia a antibióticos y generar fármacos amigables con el ambiente (Akinsemolu, 2018).

Finalmente, este trabajo revela la necesidad de continuar investigando a las cactáceas y sus endófitos no sólo para encontrar nuevas especies, sino tmabién usos con potencial aplicación para la conservación y el desarrollo sustentable. Asimismo, es necesario vincular los sectores académicos, empresariales y gubernamentales para que existan políticas públicas que fomenten la investigación y la transferencia biotecnológica.

\section{REFERENCIAS}

Aguirre-Garrido, J. F., Montiel-Lugo, D., Hernández-Rodríguez, C., Torres-Cortes, G., Millán, V., Toro, N., Martínez-Abarca, F. \& Ramírez-Saad, H. C. (2012). Bacterial community structure in the rhizosphere of three cactus species from semi-arid highlands in central Mexico. Antonie Van Leeuwenhoek, 101, 891-904. https://doi.org/10.1007/ s10482-012-9705-3

Akinsemolu, A. A. (2018). The role of microorganisms in achieving the sustainable development goals. Journal of Cleaner Production, 182, 139-155. https://doi. org/10.1016/j.jclepro.2018.02.081

Ayala, M. D. C. N. A., Castillo, F. D. H., Alcalá, E. I. L., Pérez, A. S. L., Canché, C. N. A. \& García, J. R. (2020). Efecto biológico de nanopartículas cargadas conácido indolacético microbiano en parámetros morfométricos de tomate. Revista Mexicana de Ciencias Agrícolas, 11(3), 507-517. https:// doi.org/10.29312/remexca.v11i3.1919

Barrales-Cureño, H. J. \& De la Rosa M., R. (2014). Uso de hongos endófitos en la producción del fármaco anti-cáncer Taxol. Biotecnología Vegetal, 14(1), 3-13. https://revista. ibp.co.cu/index.php/BV/article/view/23/423

Bashan, Y., Li, C. Y., Lebsky, V. K., Moreno, M. \& De Bashan, L. E. (2002). Primary colonization of volcanic rocks by plants in arid Baja California, Mexico. Plant Biology, 4(3), 392-402. https://doi.org/10.1055/s-2002-32337

Begoude, B. A. D., Slippers, B., Wingfield, M. J. \& Roux, J. (2011). The pathogenic potential of endophytic Botryosphaeriaceous fungi on Terminalia species in Cameroon. Forest Pathology, 41(4), 281-292. https://doi. org/10.1111/j.1439-0329.2010.00671.x

Bellenger, J. P., Darnajoux, R., Zhang, X. \& Kraepiel, A. M. L. (2020). Biological nitrogen fixation by alternative nitrogenases in terrestrial ecosystems: a review. Biogeochemistry, 149(1), 53-73. https://doi. org/10.1007/s10533-020-00666-7

Bertetti, D., Ortu, G., Gullino, M. \& Garibaldi, A. (2017). Identification of Fusarium oxysporum f. sp. opuntiarumon 
new hosts of the Cactaceae and Euphorbiaceae families. Journal of Plant Pathology, 99(2), 347-354. http:// www.jstor.org/stable/44686779

Bettin, F., Cousseau, F., Martins, K., Boff, N. A., Zaccaria, S., da Silveira, M. M. \& Dillon, A. J. P. (2019). Phenol removal by laccases and other phenol oxidases of Pleurotus sajor-caju PS-2001 in submerged cultivations and aqueous mixtures. Journal of Environmental Management, 236, 581-590. https://doi.org/10.1016/j.jenvman.2019.02.011

Bezerra, J. D. P., Santos, M. G., Barbosa, R. N., Svedese, V. M., Lima, D. M., Fernandes, M. J. S., Gomes, B. S., Paiva, L. M. \& Souza-Motta, C. M. (2013). Fungal endophytes from cactus Cereus jamacaru in brazilian tropical dry forest: a first study. Symbiosis, 60(2), 53-63.https://doi.org/10.1007/ s13199-013-0243-1

Bezerra, J. D. P., de Azevedo, J. L. \& Souza-Motta, C. M. (2017). Why study endophytic fungal community associated with cacti species? En: de Azevedo J., Quecine M. (Eds.) Diversity and Benefits of Microorganisms from the Tropics (pp. 21-35). Cham: Springer. https://doi.org/10.1007/9783-319-55804-2 2

Bulla, L. M. C., Polonio, J. C., de Brito Portela-Castro, A. L., Kava, V., Azevedo, J. L. \& Pamphile, J. A. (2017). Activity of the endophytic fungi Phlebia sp. and Paecilomyces formosus in decolourisation and the reduction of reactive dyes' cytotoxicity in fish erythrocytes. Environmental Monitoring and Assessment, 189(2), 88. https://doi. org/10.1007/s10661-017-5790-0

Bulgarelli, D., Rott, M., Schlaeppi, K., van Themaat, E. V. L., Ahmadinejad, N., Assenza, F., Rauf, P., Huettel, B., Reinhardt, R., Schmelzer, E., Peplies, J., Glockner, F. O., Amann, R., Eickhorst, T. \& Schulze-Lefert, P. (2012). Revealing structure and assembly cues for Arabidopsis root-inhabiting bacterial microbiota. Nature, 488(7409), 91-95. DOI: 10.1038/nature11336

Camarena-Pozos, D. A., Flores-Núñez, V. M., López, M. G., López-Bucio, J. \& Partida-Martínez, L. P. (2019). Smells from the desert: microbial volatiles that affect plant growth and development of native and non-native plant species. Plant, Cell \& Environment, 42(4), 1368-1380. https://doi.org/10.1111/pce.13476

Camarena-Pozos, D. A., Flores-Núñez, V. M., López, M. G. \& Partida-Martínez, L. P. (2021). Fungal volatiles emitted by members of the microbiome of desert plants are diverse and capable of promoting plant growth. Environmental Microbiology, 23(4), 2215-2229. https:// doi.org/10.1111/1462-2920.15395

Cardona, M., Osorio, J. \& Quintero, J. (2009). Degradación de colorantes industriales con hongos ligninolíticos. Revista Facultad de Ingeniería Universidad de Antioquía, (48), 27-37. http://www.scielo.org.co/scielo.php?script=sci arttext\&pid=S0120-62302009000200003\&lng=en\&tlng=es.

Chávez-Ambriz, L. A., Hernández-Morales, A., CabreraLuna, J. A., Luna-Martínez, L. \& Pacheco-Aguilar, J. R.
(2016). Aislados de Bacillus provenientes de la rizosfera de cactus incrementan la germinación y la floración en Mammillaria spp. (Cactaceae). Revista Argentina de Microbiología, 48(4), 333-341. https://doi.org/10.1016/j. ram.2016.09.001

Challenger, A. \& Soberón, J. (2008). Los ecosistemas terrestres, en Capital natural de México, Vol. I: Conocimiento actual de la biodiversidad. Comisión Nacional para el Conocimiento y Uso de la Biodiversidad CONABIO, México, pp. 87-108. https://bioteca.biodiversidad.gob.mx/janium/ Documentos/13309.pdf

Clay, K. (1989). Clavicipitaceous endophytes of grasses, their potential as biocontrol agents. Mycological Research, 92(1), 1-12. https://doi.org/10.1016/S0953-7562(89)80088-7

CONABIO (comp.) (2021). Catálogo de autoridades taxonómicas de especies de flora y fauna con distribución en México. Familia Cactaceae. Base de datos del Sistema Nacional de Información sobre Biodiversidad SNIBCONABIO, México.

Conn, V. M. \& Franco, C. M. (2004). Analysis of the endophytic actinobacterial population in the roots of wheat (Triticum aestivum L.) by terminal restriction fragment length polymorphism and sequencing of $16 \mathrm{~S}$ rRNAclones. Applied and Environmental Microbiology, 70(3), 1787-1794. 10.1128/aem.70.3.1787-1794.2004

Cui, M. \& Nobel, P. S. (1992). Nutrient status, water uptake and gas exchange for three desert succulents infected with mycorrhizal fungi. New Phytologist, 122(4), 643-649. https://doi.org/10.1111/j.1469-8137.1992.tb00092.x

Davis, E. C. \& Shaw, A. J. (2008). Biogeographic and phylogenetic patterns in diversity of liverwort-associated endophytes. American Journal of Botany, 95(8), 914-924. https://doi.org/10.3732/ajb.2006463

De Bashan, L. E., Hernandez, J. P. \& Bashan, Y. (2012). The potential contribution of plant growth-promoting bacteria to reduce environmental degradation - A comprehensive evaluation. Applied Soil Ecology, 61, 171-189. https://doi. org/10.1016/j.apsoil.2011.09.003

De Castro, C. P., N., Dos Santos, R. C., Cunha, M., D., Rodrigues, F., J., De Souza, F., E. M., Antinarelli, L. M. R., Soares, C., E., Ribeiro, A. \& Scio, E. (2012). Cytotoxic and antioxidant activity of Pereskia aculeata Miller. Pharmacology OnLine, 3, 63-69. https://pharmacologyonline.silae.it/files/ archives/2012/vol3/PhOL_2012_3_A009_015_Nicolas.pdf

Delaye, L., García-Guzmán, G. \& Heil, M. (2013). Endophytes versus biotrophic and necrotrophic pathogens-are fungal lifestyles evolutionarily stable traits? Fungal Diversity, 60(1), 125-135. https://doi.org/10.1007/s13225013-0240-y

Devi, P.A. (2019). Detection of antibiotic genes from endophytic Pseudomonas fluorescens of cotton. BIOINFOLET-A Quarterly Journal of Life Sciences, 16(3), 146153. http://www.indianjournals.com/ijor. aspx target $=$ ijor:bil\&volume $=16 \&$ issue $=3 \&$ article $=008$ 
Dini-Andreote, F. (2020). Endophytes: the second layer of plant defense. Trends in Plant Science, 25(4), 319-322. DOI: 10.1016/j.tplants.2020.01.007

Eke, P., Kumar, A., Sahu, K. P., Wakam, L. N., Sheoran, N., Ashajyothi, M., Patel,A.\& Fekam, F. B. (2019). Endophytic bacteria of desert cactus (Euphorbia trigonas Mill) confer drought tolerance and induce growth promotion in tomato (Solanum lycopersicum L.). Microbiological Research, 228, 126302. https://doi.org/10.1016/j.micres.2019.126302

Enebe, M. C. \& Babalola, O. O. (2018). The influence of plant growth-promoting rhizobacteria in plant tolerance to abiotic stress: a survival strategy. Applied Microbiology and Biotechnology, 102(18), 7821. DOI: 10.1007/s00253018-9214-z

Ferrer-Cervantes, M. E., Méndez-González, M. E., QuintanaAscencio, P. F., Dorantes, A., Dzib, G. \& Durán, R. (2012). Population dynamics of the cactus Mammillaria gaumeri: an integral projection model approach. Population Ecology, 54, 321-334. https://doi.org/10.1007/s10144012-0308-7

Fitriani, A., Ihsan, F. \& Hamdiyati, Y. (2015). Antibacteria activity of Shewanella and Pseudomonas as endophytic bacteria from the root of Ageratum conyzoides L. Asian Journal of Applied Sciences, 3(3), 415-420. https://www. ajouronline.com/index.php/AJAS/article/view/2719

Flores, J. \& Jurado, E. (2003). Are nurse protégé interactions more common among plants from arid environments? Journal of Vegetation Science, 14(6), 911916. https://doi.org/10.1111/j.1654-1103.2003.tb02225.x

Flores-Núñez, V. M., Fonseca-García, C., Desgarennes, D., Eloe-Fadrosh, E., Woyke, T. \& Partida-Martínez, L. P. (2020). Functional signatures of the epiphytic prokaryotic microbiome of agaves and cacti. Frontiers in Microbiology, 10, 3044. https://doi.org/10.3389/ fmicb.2019.03044

Fonseca-García, C., Coleman-Derr, D., Garrido, E., Visel, A., Tringe, S. G. \& Partida-Martínez, L. P. (2016). The cacti microbiome, interplay between habitat-filtering and hostspecificity. Frontiers in Microbiology, 7, 150. https://doi. org/10.3389/fmicb.2016.00150

Fonseca-García, C., Desgarennes, D., Flores-Núñez, V. M. \& Partida-Martínez, L. P. (2018). "Chapter 12-The microbiome of desert CAM plants: lessons from amplicon sequencing and metagenomics," En: Nagarajan, M. (Ed.) Metagenomics. Cambridge, MA:Academic Press, 231-254. https://doi.org/10.1016/B978-0-08-102268-9.00012-4

Godínez, H. (2017). Las plantas y los endófitos, cómo sobrevivir en las regiones áridas y semiáridas. Elementos, 105, 39-43. https://elementos.buap.mx/directus/storage/ uploads/00000000385.pdf

Goldstein, A., Lester, T. \& Brown, J. (2003). Research on the metabolic engineering of the direct oxidation pathway for extraction of phosphate from ore has generated preliminary evidence for PQQ biosynthesis in Escherichia coli as well as a possible role for the highly conserved region of quinoprotein dehydrogenases. Biochimica et Biophysica Acta Proteins and Proteomics, 1647, 266-271. https://doi. org/10.1016/S1570-9639(03)00067-0

He, J., Lange, J., Marinos, G., Bathia, J., Harris, D., Soluch, R., Vaibhvi, V., Dines, P., Hassani, M. A., Wagner, K., ZapienCampos, R., Jaspers, C.\& Sommer, F. (2020).Advancing our functional understanding of host-microbiota interactions: a need for new types of studies. BioEssays, 42, 1900211. https://doi.org/10.1002/bies.201900211

Kavamura, V. N., Santos, S. N., da Silva, J. L., Parma, M. M., Ávila, L. A., Visconti, A., Domingues Z., T., Gouvêa T., R., Andreote, F. D. \& Soares de Melo, I. (2013). Screening of brazilian cacti rhizobacteria for plant growth promotion under drought. Microbiological Research, 168(4), 183-191. https://doi.org/10.1016/j.micres.2012.12.002

Kim, J., Jho, K. H., Choi, Y. H. \& Nam, S. Y. (2013). Chemopreventive effect of cactus (Opuntia humifusa) extracts, radical scavenging activity, pro-apoptosis, and anti-inflammatory effect in human colon (SW480) and breast cancer (MCF7) cells. Food \& Function, 4(5), 681688. https://doi.org/10.1039/C3FO30287C

Kobayashi, D. Y., Reedy, R. M., Bick, J. \& Oudemans, P. V.(2002). Characterization of a chitinase gene from Stenotrophomonas maltophilia strain 34S1 and its involvement in biological control. Applied and Environmental Microbiology, 68(3), 1047-1054. https://doi.org/10.1128/AEM.68.3.10471054.2002

Kusari, S., Hertweck, C. \& Spiteller, M. (2012). Chemical ecology of endophytic fungi: origins of secondary metabolites. Chemistry \& Biology, 19(7), 792-798. https:// doi.org/10.1016/j.chembiol.2012.06.004

Leite, L. J. V., Weber, O. M., Correia, D., Soares, M. A. \& Alves, S. J. (2015). Endophytic bacteria in cacti native to a brazilian semi-arid region. Plant and Soil, 389, 25-33. https://doi.org/10.1007/s11104-014-2344-X

Li, J. H., Wang, E. T., Chen, W. F. \& Chen, W. X. (2008). Genetic diversity and potential promotion of plant growth detected in nodule endophytic bacteria of soybean grown in Heilongjiang province of China. Soil Biology and Biochemistry, 40, 238-246. https://doi.org/10.1016/j. soilbio.2007.08.014

Li, H. Y., Wei, D. Q., Shen, M. \& Zhou, Z. P. (2012). Endophytes and their role in phytoremediation. Fungal Diversity, 54(1), 11-18. https://doi.org/10.1007/s13225012-0165-x

Li, H., Parmar, S., Sharma, V. K. \& White, J. F. (2019). Seed endophytes and their potential applications. En: Verma S., White, Jr. J. (Eds.) Seed Endophytes (pp. 35-54). Cham: Springer. https://doi.org/10.1007/978-3-030-10504-4_3

Lima, J. V. L., Weber, O. B., Correia, D., Soares, M. A. \& Senabio, J. A. (2015). Endophytic bacteria in cacti native to a Brazilian semi-arid region. Plant and Soil, 389(1-2), 25-33. https://doi.org/10.1007/s11104-014-2344-X 
López, B. R., Tinoco-Ojanguren, C., Bacilio, M., Mendoza, A. \& Bashan, Y. (2012). Endophytic bacteria of the rockdwelling cactus Mammillaria fraileana affect plant growth and mobilization of elements from rocks. Environmental and Experimental Botany, 81, 26-36. https://doi.org/10.1016/j. envexpbot.2012.02.014

Maldonado-Carmona, N., Vázquez-Hernández, M., Chávez, O. J.P., Rodríguez-Luna, S. D., Rodríguez, O. J., Sanchez, S. \& Ceapă, C. D. (2019). Impact of omics in the detection and validation of potential anti-infective drugs. Current Opinion in Pharmacology, 48, 1-7. https://doi.org/10.1016/j. coph.2019.02.008

Márquez, S. S., Bills, G. F., Herrero, N. \& Zabalgogeazcoa, I. (2012). Non-systemic fungal endophytes of grasses. Fungal Ecology, 5(3), 289-297. https://doi.org/10.1016/j. funeco.2010.12.001

Martínez-Klimova, E., Rodríguez-Peña, K. \& Sánchez, S. (2017). Endophytes as sources of antibiotics. Biochemical Pharmacology, 134, 1-17. https://doi.org/10.1016/j. bcp.2016.10.010

Mascarúa-Esparza, M. A., Villa-González, R. \& CaballeroMellado, J. (1988) Acetylene reduction and indoleacetic acid production by Azospirllum isolates from cactaceous plants. Plant Soil, 106, 91-95. https://doi.org/10.1007/ BF02371199

Miller, C. M., Miller, R. V., Garton-Kenny, D., Redgrave, B., Sears, J., Condron, M. M., Teplow, D. B. \& Strobel, G. A. (1998). Ecomycins, unique antimycotics from Pseudomonas viridiflava.Journal of Applied Microbiology, 84(6), 937-44. https://doi.org/10.1046/j.1365-2672.1998.00415.x

Muthezhilan, R., Vinoth, S., Gopi, K. \& JaffarHussain,A. (2014). Dye degrading potential of immobilized laccase from endophytic fungi of coastal sand dune plants. International Journal of ChemTech Research, 6(9), 4154-4160. http:// sphinxsai.com/2014/RTBCE/2/(4154-4160)\%20014.pdf

Paredes-Mendoza, M. \& Espinosa-Victoria, D. (2010). Ácidos orgánicos producidos por rizobacterias que solubilizan fosfato: una revisión crítica. Terra Latinoamericana, 28(1), 61-70. http://www.scielo.org.mx/scielo.php?script=sci arttext\&pid $=$ S0187-57792010000100007

Pauca, A., Talavera, C., Villasante, F., Quispe, J. \& Laura, M. (2018). Cactaceae del distrito de Atiquipa y del Área de Conservación Privada Lomas de Atiquipa: aspectos taxonómicos, ecológicos y de distribución. Arnaldoa, 25(3), 829-856. http://www.scielo.org.pe/scielo.php?script=sci arttext\&pid=S2413-32992018000300003

Pereg, L., de-Bashan, L. E. \& Bashan, Y. (2016). Assessment of affinity and specificity of Azospirillum for plants. Plant and soil, 399(1-2), 389-414. https://doi.org/10.1007/ s11104-015-2778-9

Pereira, P., Ibáñez, F., Rosenblueth, M., Etcheverry, M. \& Martínez-Romero, E. (2011). Analysis of the bacterial diversity associated with the roots of maize (Zea mays L.) through culture-dependent and culture-independent methods. International Scholarly Research Notices, 2011 , 1-10. https://doi.org/10.5402/2011/938546

Pereira, J., de Azevedo, J. \& Souza-Motta, C. (2017). Why study endophytic fungal community associated with cacti species? En: de Azevedo, J. \& Quecine, M. (Eds.), Diversity and benefits of microorganisms from the tropics (pp. 2135). Suiza: Springer International Publishing. https://doi. org/10.1007/978-3-319-55804-2_2

Petrini, O. (1991). Fungal endophytes of tree leaves. p. 179197. En: J.H.Andrews y S.S. Hirano (Eds.). Microbial ecology of leaves. Springer Verlag, New York. https://doi. org/10.1007/978-1-4612-3168-4 9

Pitiwittayakul, N. \& Tanasupawat, S. (2020). Plant GrowthPromoting endophytic Bacteria and their potential benefits in Asian countries. En: Beneficial Microbes for Sustainable Agriculture and Environmental Management (pp. 81-114). Apple Academic Press.

Porras-Alfaro, A. \& Bayman, P. (2011). Hidden fungi, emergent properties: endophytes and microbiomes. Annual review of phytopathology, 49, 291-315. DOI: 10.1146/annurevphyto-080508-081831

Puente, M. E., Bashan, Y., Li, C. Y. \& Lebsky, V. K. (2004 a). Microbial populations and activities in the rhizoplane of rock-weathering desert plants, I. Root colonization and weathering of igneous rocks. Plant Biology, 6, 629-642. https://doi.org/10.1055/s-2004-821100

Puente, M. E., Li, C. Y. \& Bashan, Y. (2004 b). Microbial populations and activities in the rhizoplane of rock weathering desert plants, II. Growth promotion of cactus seedling. Plant Biology, 6, 643-650. https://doi. org/10.1055/s-2004-821101

Puente, M. E., Li, C. Y. \& Bashan, Y. (2009). Rockdegrading endophytic bacteria in cacti. Environmental and Experimental Botany, 66, 389-401. https://doi. org/10.1016/j.envexpbot.2009.04.010

Puri, A., Padda, K. P. \& Chanway, C. P. (2017). Plant growth promotion by endophytic bacteria in nonnative crop hosts. En: Maheshwari, D. \& Annapurna K. (eds.) Endophytes: crop productivity and protection. Sustainable Development and Biodiversity, vol 16. Springer, Cham. https://doi. org/10.1007/978-3-319-66544-3_2

Ramos-Garza, J., Rodríguez-Tovar, A. V., Flores-Cotera, L. B., Rivera-Orduña, F. N., Vásquez-Murrieta, M. S., PonceMendoza, A. \& Wang, E. T. (2016). Diversity of fungal endophytes from the medicinal plant Dendropanax arboreus in a protected area of Mexico. Annals of Microbiology, 66, 991-1002. https://doi.org/10.1007/s13213-015-1184-0

Ratnaweera, P. B., de Silva, E. D., Williams, D. E. \& Andersen, R. J. (2015). Antimicrobial activities of endophytic fungi obtained from the arid zone invasive plant Opuntia dillenii and the isolation of equisetin, from endophytic Fusarium sp. BMC Complementary and Alternative Medicine, 15, 220. https://doi.org/10.1186/ s12906-015-0722-4 
Restrepo-Correa, S. P., Pineda-Meneses, E. C. \& RíosOsorio, L. A. (2017). Mecanismos de acción de hongos y bacterias empleados como biofertilizantes en suelos agrícolas: una revisión sistemática. Ciencia y Tecnología Agropecuaria, 18(2), 335-351. https://doi.org/10.21930/ rcta.vol18_num2_art:635

Ríos-León, K., Fuertes-Ruiton, C., Arroyo, J. \& Ruiz, J. (2017). Efecto quimioprotector del extracto alcaloideo de Melocactus bellavistensis (cactus globoso) sobre el cáncer de colon inducido con 1,2-dimetilhidrazina en ratas. Revista Peruana de Medicina Experimental y Salud Pública, 34 (1), 70-75.https://doi.org/10.17843/rpmesp.2017.341.2768

Rodríguez-Ruíz, E. R., Poot-Poot, W. A., Rangel-Lucio, J. A., Vaquera-Huerta, H., González-Gaona, O. J. \& TreviñoCarreón, J. (2018). Germinación in vitro de biznaga cabuchera. Revista Mexicana de Ciencias Agrícolas, 9(3), 691-699. http://www.scielo.org.mx/pdf/remexca/ v9n3/2007-0934-remexca-9-03-691.pdf

Rosenblueth, M. \& Martínez-Romero, E. (2006). Bacterial endophytes and their interactions with hosts. American Phytopathological Society,19, 827- 837. https://doi. org/10.1094/MPMI-19-0827

Ruvalcaba-Ruiz, D., Rojas-Bravo, D. \& Valencia-Botín, A. J. (2010). Propagación in vitro de Coryphantha retusa (Britton \& Rose) un cactus endémico y amenazado. Tropical and Subtropical Agroecosystems, 12(1), 139-143. https://www. redalyc.org/articulo.oa?id=93913074015

Saikkonen, K., Faeth, S. H., Helander, M. \& Sullivan, T. J.(1998). Fungal endophytes: a continuum of interactions with host plants. Annual review of Ecology and Systematics, 29(1), 319-343.https://doi.org/10.1146/annurev.ecolsys.29.1.319

Salazar, J. R., Martínez-Vazquez, M., Cespedes, C. L., RamírezApan, T., Nieto-Camacho, A., Rodríguez-Silverio, J. \& Flores-Murrieta, F. (2011). Anti-inflammatory and cytotoxic activities of chichipegenin, peniocerol, and macdougallin isolated from Myrtillocactus geometrizans (Mart. Ex Pfeiff.) Con. Zeitschrift fur Naturforschung - Section C Journal of biosciences, 66(1-2), 24-30. DOI: 10.1515/znc-2011-1-204

Samad,A.,Antonielli, L., Sessitsch,A., Compant, S. \& Trognitz, F. (2017). Comparative genome analysis of the vineyard weed endophyte Pseudomonas viridiflava CDRTc14 showing selective herbicidal activity. Scientific Reports. 7, 17336. https://doi.org/10.1038/s41598-017-16495-y

Sánchez-Fernández, R. E., Sánchez-Ortiz, B. L., SandovalEspinosa, Y. K. M., Ulloa-Benítez,A.,Armendáriz-Guillén, B., García-Méndez, M. C. \& Macías-Rubalcava, M. L. (2013). Hongos endófitos, fuente potencial de metabolitos secundarios bioactivos con utilidad en agricultura y medicina. TIP Revista Especializada en Ciencias QuímicoBiológicas, 16(2), 132-146. https://doi.org/10.1016/S1405888X(13)72084-9

Schouten, A. (Ed.) (2019). Endophyte biotechnology: potential for agriculture and pharmacology. CABI, UK. https://doi. org/10.1079/9781786399427.0000
Schulz, B., Römmert,A. K., Dammann, U., Aust, H. J. \& Strack, D. (1999). The endophyte-host interaction: a balanced antagonism? Mycological Research, 103(10), 1275-1283. https://doi.org/10.1017/S0953756299008540

Schulz, B. \& Boyle, C. (2006). What are endophytes? En: Schulz, B. J. E., Boyle, C. J. C., Sieber, T. N. (Eds.). Microbial Root Endophytes. Soil Biology, vol. 9. Springer, Berlin, Heidelberg. https://doi.org/10.1007/3-540-33526-9_1

Sessitsch, A., Howieson, J. G., Perret, X., Antoun, H. \& Martinez-Romero, E. (2002). Advances in Rhizobium research. Critical Reviews in Plant Sciences, 21, 323-378. https://doi.org/10.1080/0735-260291044278

Shahid, I., Rizwan, M., Baig, D. N., Saleem, R. S., Malik, K. A. \& Mehnaz, S. (2017). Secondary metabolites production and plant growth promotion by Pseudomonas chlororaphis and P. aurantiaca strains isolated from cactus, cotton, and para grass. Journal of microbiology and biotechnology, 27(3), 480-491. https://doi.org/10.4014/ jmb.1601.01021

Shedbalkar, U.,Adki, V., Jadhav, J. \& Bapat, V. (2010). Opuntia and other cacti, applications and biotechnological insights. Tropical Plant Biology, 3, 136-150. https://doi.org/10.1007/ s12042-010-9055-0

Silva-Hughes, A. F., Wedge, D. E., Cantrell, C. L., Carvalho, C. R., Pan, Z., Moraes, R. M., Madoxx, V. L. \& Rosa, L. H. (2015). Diversity and antifungal activity of the endophytic fungi associated with the native medicinal cactus Opuntia humifusa (Cactaceae) from the United States. Microbiological Research, 175, 67-77. https://doi. org/10.1016/j.micres.2015.03.007

Singh, R. K., Shrivastava, A., Yadav, A. \& Srivastava, A. K. (2020). Endophytic bacteria as a source of bioactive compounds. En: Microbial Endophytes (pp. 175-188). Woodhead Publishing. https://doi.org/10.1016/B978-012-818734-0.00008-5

Soumare,A., Diedhiou, A. G., Thuita, M., Hafidi, M., Ouhdouch, Y., Gopalakrishnan, S. \& Kouisni, L. (2020). Exploiting biological nitrogen fixation: a route towards a sustainable agriculture. Plants, 9(8), 1011. https://doi.org/10.3390/ plants9081011

Suryanarayanan, T. S., Wittlinger, S. K. \& Faeth, S. H. (2005). Endophytic fungi associated with cacti in Arizona. Mycological Research, 109, 635-639. https://doi. org/10.1017/S0953756205002753

Suryanarayanan, T. S. (2013). Endophyte research: going beyond isolation and metabolite documentation. Fungal ecology, 6(6), 561-568. https://doi.org/10.1016/j. funeco.2013.09.007

Swarnalakshmi, K., Senthilkumar, M. \& Ramakrishnan, B. (2016). Endophytic actinobacteria: nitrogen fixation, phytohormone production, and antibiosis. En: Subramaniam G., Arumugam S., Rajendran V. (eds.) Plant growth promoting actinobacteria. Springer, Singapore. https://doi. org/10.1007/978-981-10-0707-1_8 
Tochhawng, L., Mishra, V. K., Passari, A. K. \& Singh, B. P. (2019). Endophytic fungi: role in dye decolorization. En: Singh, B. (Ed.) Advances in endophytic fungal research: present status and future challenges. Springer, Cham. 1. https://doi.org/10.1007/978-3-030-03589-1_1

Wan, J. H. C. \& Wong, M. H. (2004). Effects of earthworm activity and $\mathrm{P}$-solubilizing bacteria on $\mathrm{P}$ availability in soil. Journal of Plant Nutrition and Soil Science 167, 209-213. https://doi.org/10.1002/jpln.200321252

Wang, E. T., Tan, Z. Y., Guo, X. W., Duran, R., Boll, G. \& Martínez-Romero, E. (2006). Diverse endophytic bacteria isolated from a leguminous tree Conzattia multiflora grown in Mexico. Archives of Microbiology, 186, 251-259. https:// doi.org/10.1007/s00203-006-0141-5
Yadav, A. N. (2021). Beneficial plant-microbe interactions for agricultural sustainability. Journal of Applied Biology \& Biotechnology, 9, 1-4. DOI: 10.7324/JABB.2021.91ed

Yan, L., Zhu, J., Zhao, X., Shi, J., Jiang, C. \& Shao, D. (2019). Beneficial effects of endophytic fungi colonization on plants. Applied microbiology and biotechnology, 103(8), 3327-3340. https://doi.org/10.1007/s00253-019-09713-2

Zareisedehizadeh, S., Tan, C. H. \& Koh, H. L. (2014). A review of botanical characteristics, traditional usage, chemical components, pharmacological activities, and safety of Pereskia bleo (Kunth) DC. Evidence-Based Complementary and Alternative Medicine, 2014, 1-11. https://doi.org/10.1155/2014/326107 